\title{
Review of quantitative and qualitative studies on U.S. public perceptions of synthetic biology
}

\author{
Eleonore Pauwels
}

Received: 27 April 2009/Revised: 7 July 2009/ Accepted: 27 July 2009

(C) The Author(s) 2009. This article is published with open access at Springerlink.com

\begin{abstract}
How are public perceptions towards synthetic biology likely to evolve? Which factors will impact the framing of this emerging technology, its benefits and risks? The objective of this article is not to draw exhaustive conclusions about public perceptions of synthetic biology, but rather to provide readers with a review of integrated findings from the first quantitative and qualitative research ever conducted on this subject in the United States. Synthetic biology survey research shows two clear findings. The first is that most people know little or nothing about synthetic biology. Second, notwithstanding this lack of knowledge, respondents are likely to venture some remark about what they think synthetic biology is and the tradeoff between potential benefits and potential risks. Finding only some support for the "familiarity argument" - according to which support for emerging technologies will likely increase as awareness of them develops-this article suggests that analogs to cloning, genetic engineering and stem cell research appear to be recurrent in the framing process of synthetic biology. The domain of application seems to be another decisive factor in the framing of synthetic biology. Finally, acceptance of the risk-benefit tradeoff of synthetic biology seems to depend on having an oversight structure that would prove able to manage unknowns,
\end{abstract}

Electronic supplementary material The online version of this article (doi:10.1007/s11693-009-9035-6) contains supplementary material, which is available to authorized users.

\section{E. Pauwels $(\bowtie)$}

Woodrow Wilson International Center for Scholars,

One Woodrow Wilson Plaza, 1300 Pennsylvania Avenue,

NW, Washington, DC 20004-3027, USA

e-mail: eleonore.pauwels@wilsoncenter.org human and environmental concerns, and long-term effects. The most important conclusion of this study is the need for additional investigation of factors that will shape public perceptions about synthetic biology, its potential benefits, and its potential risks.

Keywords Public perceptions · Focus groups · Framing - Cognitive shortcuts to previous technologies . Risk-benefit tradeoff . Trust in institutions

\section{Introduction}

Synthetic biology is a field that promises advances in energy, healthcare, and other areas. How much do Americans know about it? Do members of the public think potential benefits of this emerging technology will outweigh potential risks?

These questions were part of a representative national telephone survey of 1,003 U.S. adults conducted by Peter D. Hart Research Associates (hereafter, Hart survey) in August 2008 on the behalf of the Project on Emerging Nanotechnologies at the Woodrow Wilson International Center for Scholars (Hart Research Associates 2008). The poll marks the first time Americans have been asked in a phone survey about synthetic biology. A few months before, in March 2008, the Cultural Cognition Project (CCP) at Yale Law School conducted an on-line survey study of 1,500 Americans (hereafter, CCP survey) aimed at determining what members of the public think about potential benefits and potential risks of synthetic biology (Kahan et al. 2009).

However, survey data of this kind seldom provide a sufficiently detailed picture from which to adequately interpret national trends. Survey research should be 
complemented by qualitative contextual studies intended to explore popular understandings and images of new technology as well as longitudinal media analysis designed to reveal significant patterns in press coverage. ${ }^{1}$

To this end, this contribution also uses the findings of two focus group sessions conducted in Baltimore, Maryland, on August 6, 2008, among (18-65 year old) adultsone among women and one among men-to contextualize the results of the two above-mentioned quantitative surveys and to explore more in depth both uninformed and informed perceptions of synthetic biology in the United States.

Both surveys focused on the questions of U.S. public awareness of synthetic biology and perceptions of its riskbenefit tradeoff. The Hart survey also included a third open-ended question on the words and images used by members of the public to describe synthetic biology. This constitutes a set of representative data that can be used to gauge general appraisal of synthetic biology risks in the United States. However, the two focus groups added insights on what specific applications may be welcomed by members of the public and which types of perceived risks may lead to public uneasiness. The focus groups also provided data about the framing of synthetic biology that would be least accessible without the kind of interaction found in a group setting-listening to others' verbalized experiences stimulates ideas and experiences in participants. Finally, the focus groups also gave an appraisal of U.S. public confidence in different institutions/communities to regulate and tell the truth about synthetic biology.

The objective of this article is not to draw exhaustive conclusions about public perceptions of synthetic biology, but rather to provide readers with an integrated review of findings from the first quantitative and qualitative research ever conducted on this subject in the United States. However, while two reports ${ }^{2}$ have already been published on the previously mentioned quantitative data, no article has yet reported on the qualitative data and this is why, in this context, the present article gives qualitative insight into what words, images, and cognitive shortcuts to previous technologies members of the public use to frame synthetic biology, what applications they potentially welcome, what kind of perceived risks would prove acceptable to them, and what actors and parameters would increase their trust in society's ability to manage synthetic biology's technological risks.

\footnotetext{
1 The following report (Pauwels and Ifrim 2008) is devoted to analyzing synthetic biology press coverage in the United States and Europe during 2003-2008. When the results of this media analysis confirm or contradict some of the present U.S. public perception data, it has been mentioned in the footnotes.

${ }^{2}$ Cf. Hart Research Associates (2008), Kahan et al. (2009).
}

\section{Materials and methods}

Quantitative studies ${ }^{3}$

From August 20 to 25, 2008, Peter D. Hart Research Associates conducted a nationwide survey among 1,003 adults about awareness of and attitudes towards synthetic biology. At a 95\% confidence level, the data's margin of error is \pm 3.1 percentage points.

The CCP survey was based on a sample consisting of 1,500 U.S. adults recruited to be members of a nationally representative online panel by Polimetrix, a firm that specializes in academic and commercial public opinion research. The study was conducted using Polimetrix's online facilities: cf. http://www.polimetrix.com/documents/ YGPolimetrixSampleMatching.pdf).

\section{Qualitative study}

The Project on Emerging Nanotechnologies at the Woodrow Wilson International Center for Scholars and Peter D. Hart Research Associates conducted two focus groups in Baltimore, Maryland on August 6, 2008, with (18-65 year old) adults-one made up of women (11) and one made up of men (9) - to explore both uninformed and informed impressions of synthetic biology. These two focus groups were part of a continuing effort by the Project to analyze public perceptions of emerging technologies and public attitudes toward the governance of these technologies and their societal implications. The results of these focus groups are limited and should not be considered to represent anything more than a sample of public opinion toward synthetic biology and should not be used to draw definitive conclusions. Detailed information on the focus groups, i.e. experimental conditions and participants' background, is provided in supplementary materials.

\section{Results}

Public awareness of synthetic biology and initial ${ }^{4}$ perception of risk-benefit tradeoff

Most Americans remain unfamiliar with synthetic biology. Some $82 \%$ of respondents to the online CCP survey reported knowing "nothing at all" or "just a little" about

\footnotetext{
${ }^{3}$ Further information on the methods and materials used in both quantitative surveys has been extensively developed in the two following reports: Kahan et al. (2009), Hart Research Associates (2008).

${ }^{4}$ In the present article, the term "initial" refers to the assessment of the participants' awareness of synthetic biology before any introduction to the science.
} 
synthetic biology while only $16 \%$ reported knowing a "moderate amount" and only $2 \%$ reported knowing "a lot" (Kahan et al. 2008b, 2009). The nationwide phone survey conducted by Peter D. Hart Research Associates indicates similar figures: just $9 \%$ of Americans said that they have heard a lot or some about synthetic biology, including a mere $2 \%$ who indicate they have heard a lot about it; another $22 \%$ of adults said they have heard just a little about this area of science, and a full $67 \%$ have heard nothing at all about it (Hart Research Associates 2008). The small proportion of Americans who express any awareness of synthetic biology are most likely to say that they have heard about it on television, from the news media, or in a newspaper. ${ }^{5}$

Both the CCP and the Hart surveys show two clear findings. The first is that most people know little or nothing about synthetic biology. Second, notwithstanding this lack of knowledge, people are likely to express an initial opinion about synthetic biology, its potential benefits, and its potential risks. According to the Hart survey, 7 in 10 Americans offer some remark about what they think synthetic biology is or what images, words and phrases it conjures in their minds despite their low level of awareness of the technology (Hart Research Associates 2008). Even with this low level of awareness, a two-thirds majority of adults $(66 \%)$ is willing to express an initial opinion regarding the tradeoff between potential benefits and potential risks of synthetic biology. They are slightly more likely to think that the benefits will outweigh the risks (21\%) than the risks will outweigh the benefits (16\%), while $29 \%$ believe that the risks and benefits will be equal.

These last findings are confirmed by the CCP survey in which, despite a similar degree of unfamiliarity, most subjects ventured an opinion one way or the other on the potential benefits and potential risks of synthetic biology (Kahan et al. 2008b, 2009). Again, they are more likely to agree that the benefits of synthetic biology will outweigh its risks (54\%), while $43 \%$ disagree with this proposition.

The discussions among the focus groups' participants conformed to this general pattern. Only 6 among the 20 total participants in the focus groups (30\%) said that they knew what synthetic biology was prior to receiving any background readings. These results indicate the relatively limited level of awareness of the field among the participants and corroborate the results of the quantitative studies. However, even with limited awareness of synthetic biology, a solid majority of the focus groups' participants were willing to give a brief description of what they think

\footnotetext{
5 Pauwels and Ifrim (2008, p. 17) indicates that the number of news stories that mention the potential benefits of the technology outnumbered those mentioning potential risks, with more than $50 \%$ of American news stories exclusively mentioning the potential benefits.
}

synthetic biology is and elaborate on its potential before receiving any information about the technology.

Informed $^{6}$ perception of the risk-benefit tradeoff of synthetic biology

The CCP survey suggests that how familiar respondents reported being with synthetic biology was not strongly associated with their perceptions of its risks and benefits (Kahan et al. 2008b, 2009). Fifty-six percent of the respondents who were "relatively familiar" with synthetic biology (that is, those who professed to know a "moderate amount" or "a lot") agreed that its benefits would outweigh its risks along with $54 \%$ of those who were "relatively unfamiliar" (those who reported knowing either "a little" or "nothing at all" about it). Because the $56 \%$ of those who professed being familiar with synthetic biology mirrors the $54 \%$ of those who professed being relatively unfamiliar, one might infer that the knowledge vanguard includes both groups predisposed to see risks and groups predisposed to see benefits in this novel technology. This finding is only modestly surprising. Previous studies have illustrated that knowledge is a weak predictor of public attitudes (Gaskell et al. 2004; Douglas and Wildavsky 1982; Bauer et al. 2007) and have given evidence for the rejection of the familiarity hypothesis-according to which, support for emerging technologies increases as awareness of them develops (Kahan et al. 2008a; Macoubrie 2006).

Converging with the above-mentioned results of the CCP survey, the Hart survey shows that, after learning about synthetic biology and being informed of its potential risks and benefits, the greatest shift in public opinion is toward risks (see Fig. 1). Upon hearing the information about synthetic biology, 29\% of adults say that the risks and the benefits are equal (no change from the same question measuring non-informed perception), $28 \%$ believe the benefits outweigh the risks (a 7-point increase), and $35 \%$ think the risks outweigh the benefits (a 19-point increase).

As an illustration of these quantitative findings, a comparison of the uninformed and informed perceptions of the focus groups' participants reveals that how much participants knew about synthetic biology had little relation to their framing of its risks and benefits. In fact, confronting the focus group participants with balanced information about synthetic biology did not simply lead to more or less support for the technology but to a more nuanced level of

\footnotetext{
${ }^{6}$ In the present article, the term "informed" refers to opinions expressed after participants were asked to read a brief description of synthetic biology that consisted of a one-sentence definition and a paragraph explaining the basic facts of the science.
} 


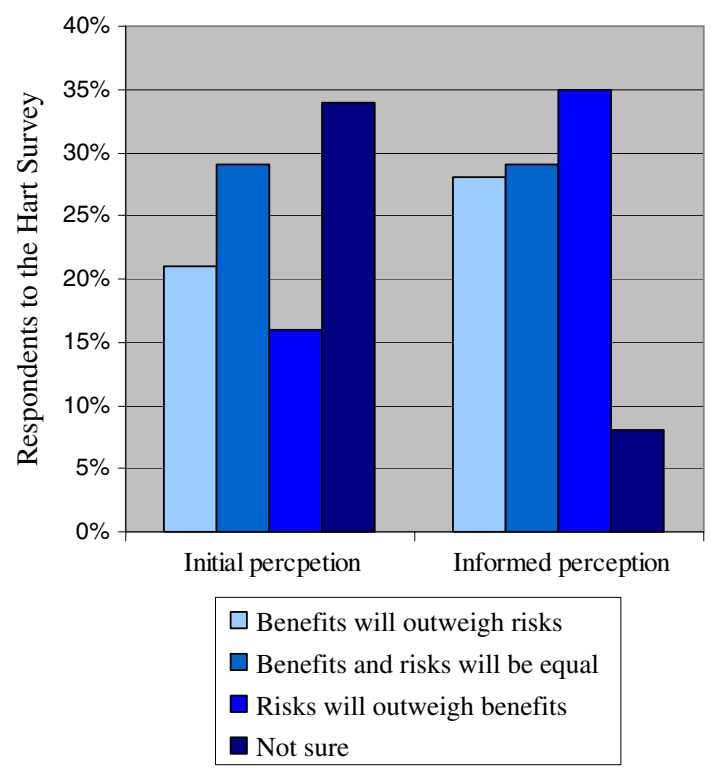

Fig. 1 Initial and informed perceptions of the synthetic biology riskbenefit tradeoff ( $n=1003$, Hart Research Associates 2008)

discussion which inter alia shows the participants' relative ambivalence toward "creation of life" or "playing God"7 aspects of the technology. The qualitative approach adopted here yields additional insights into how lay people frame synthetic biology and its implications.

\section{Framing synthetic biology}

The Hart survey provides us with representative answers to the following single open-ended question: "Regardless of how much you have heard about synthetic biology, what do you think synthetic biology is? What ideas, images, words, or phrases do you associate with synthetic biology?" Nearly 3 in 10 (29\%) adults say: "I do not know" or "nothing". Nearly 3 in 10 (29\%) adults declare that synthetic biology is something man-made, artificial, fake, unnatural, or not real. One in $10(11 \%)$ says that it has to do

\footnotetext{
7 What experts call the "playing God" argument is well explained in the following excerpt of Scheufele et al. (2008, p. 1): "Recent research also suggests that religious beliefs may be part of the value system people use when they make sense of science and technology more broadly. This may be due to perceptions that there are normative inconsistencies between science and religious beliefs, illustrated by the view that science interferes with nature-or is equivalent to playing God-and is therefore incompatible with strong religious beliefs. For instance, researchers have found that moral issues and concerns about "unnatural" technologies were important in explaining negative attitudes towards genetically modified (GM) organisms, which were seen as disturbing nature and natural processes, and perceived as risky and immoral. The potential conflict between religiosity and science has been much more salient for nanotechnology, in particular with respect to nano-bio-info (NBIC) technologies that may, in the future, enable us to create life and intelligence (our emphasis) at the nanoscale without divine intervention."
}

with cloning, genetic engineering, or genetic manipulation; another $7 \%$ say it has to do with altering biology or biological make-up; and 4\% explain it as creating artificial life (Hart Research Associates 2008). The inclusion in the Hart survey of this open-ended question gives us a unique opportunity to compare the Hart finding to the discussions engaged by the participants in the focus groups about the framing of synthetic biology.

The discussions among the focus groups participants illustrate the findings of the Hart survey, according to which the most common reply to the question of what is synthetic biology is a variation on the theme that synthetic biology is "man-made," "artificial," or "not natural".

\section{Initial descriptors used by the focus groups' participants}

When trying to describe synthetic biology in their own words, participants relied heavily on adjectives and images (or products) that might be associated with synthetic biology. The images and words that, for the participants, epitomized the development of synthetic biology, were borrowed from medical or industrial activities-products such as medicines, vaccines, and plastics. It is worth noting that the adjective "man-made" was cited more than five times in each focus group during the description process. Other recurrent adjectives were "artificial," "created," "unnatural," and "synthetic." When elaborating on the purpose of the technology, they made extensive use of the verbs "altering" and "duplicating," while the expression "improving the quality of life" was also introduced several times.

Impressions and descriptions of synthetic biology were explored and discussed in depth in the focus groups. These discussions led to brief definitions (see Fig. 2) being given by the focus groups' participants which, to some extent, mirror the emphasis on the "man-made" aspects ("replacement" by artificial objects or robots) of synthetic biology as mentioned in responses in the Hart survey.

\section{Initial analogs used by the focus groups' participants}

Participants also tended to describe synthetic biology by drawing parallels with other biotechnology or biomedical fields. These analogs (Table 1) show how participants framed the concept of synthetic biology and what other technologies they associated with it. And it is why these analogs or references might be crucial to anticipating the lines along which future public debates about synthetic biology may evolve.

Before being given a definition of synthetic biology and being informed of potential applications for the technology, participants tended to view the field in relation to previous technologies such as cloning, stem cell research, and 
Fig. 2 Some brief definitions of synthetic biology given by the focus groups' participants

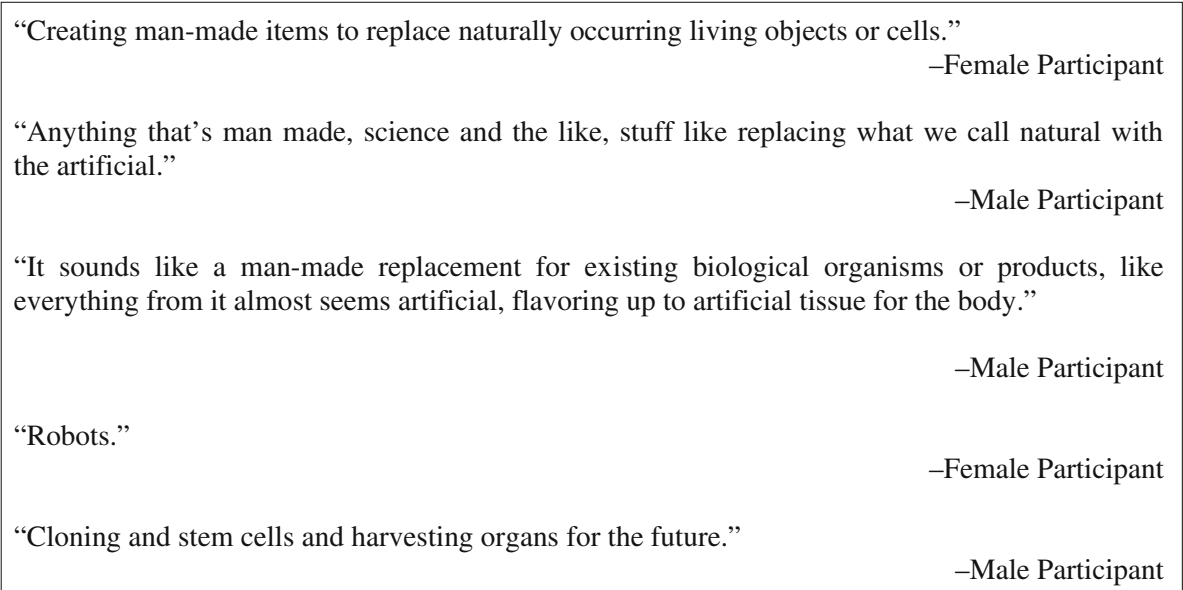

Table 1 Analogs used in focus group discussions of synthetic biology

\begin{tabular}{ll}
\hline $\begin{array}{l}\text { Focus Group } 1(\text { female } \\
\text { participants, } n \text { female }=11)\end{array}$ & $\begin{array}{l}\text { Focus Group } 2(\text { male } \\
\text { participants, } n \text { male }=9)\end{array}$ \\
\hline Cloning & Cloning, cloning procedures \\
Genetic engineering & Genetic engineering \\
Stem cell research & Stem cell research \\
& Recombinant DNA research \\
& Regenerative medicine \\
\hline
\end{tabular}

genetic engineering. In Focus Group 1, when attempting to describe synthetic biology, one of the female participants mentioned the activity of "cloning, trying to change naturally occurring living objects into man-made objects" (emphasis added). While professing his lack of knowledge, one male participant in Focus Group 2 was capable of making more accurate references to existing technologies: "I am not really sure. Genetic Engineering and cloning come to my mind. Maybe something to do with recombining DNA and technology" (emphasis added). When the focus groups' moderator asked participants to elaborate on these initial analogs to provide a brief definition of synthetic biology, similar references came up in the discussion. In Focus Group 2, one of the male participants defined synthetic biology as "continuing to utilize cloning procedures to 'grow' human organs from stem cells, to perhaps genetically engineering whole organisms" (emphasis added).

References made to existing technologies are a window into participants' initial perceptions of synthetic biology. These analogs provide a way of looking ahead by looking back. They contribute to the framing of the technology by the participants and reveal the cognitive shortcuts that they will likely use when learning more about synthetic biology.

The next section compares preliminary analogies used by the participants with their comments and reactions after being given information about synthetic biology. This comparison allows us to evaluate the influence of new information on the attitudes and perceptions of the participants towards synthetic biology and to assess the extent to which they will rely on their previously conceived cognitive references or shortcuts to process the information.

\section{Analogs used to express reactions to synthetic biology readings}

Analogs associated with synthetic biology were generally similar before and after participants had read an explanatory paragraph about synthetic biology. References to cloning, stem cell research, and genetic engineering were the most popularly used analogs to express reactions to synthetic biology readings in both focus groups and were used to make positive and negative points about synthetic biology. For example, one of the female participants referenced cloning when speaking about the field's potential medical applications: "It makes me feel, I was saying that it makes me think of cloning and all that, the engineering, and it gives me great possibilities as far as maybe detecting genetic, you know, disorders and whatever and trying to find some cures or ways of doing something to like an embryo, whatever, to get rid of the problems." Another female participant criticized the instrumental aspect of the potential use of genetic engineering: "It sounds like it's a boutique little shop area, and you sit out there wherever you want, and everything is tailored to what you need and what you desire. But, you know, kind of going back to if we start genetically altering kids or whatever in the future, it may not necessarily lead to the result that we would have expected."

While focusing at first on the science-fiction scenarios linked to the use of cloning and genetic engineeringreferences were made to Jurassic Park and Gattaca-the debate among the male participants succeeded in distinguishing 
cloning processes from the synthetic biology approach: "But this seems like you just clone. But, well, we're not cloning. We're just creating our own DNA."

Also notable were the general references to stem cell research that appeared in both focus groups. However, among the male participants, the point was made that, in the case of stem cell research, the United States had failed to fully develop the research potential, especially in comparison with other countries: "Look at the problem they have with cloning, because they were worried they were going to clone a man. Then you go over to the other side, the religious side, and you're dealing, I'm not getting into that, obviously, but you're dealing with all that. So, I mean, like with the stem cells...because of this...but yet they could have saved a lot of people." This reasoning led this particular participant to reconsider the "playing God" analog used several times in the focus groups' discussions to characterize the ramifications of synthetic biology:

So I believe if they try this, you're going to have religious people coming out, saying that you're playing God, and you can't do this. And other people will come out and say, well, God put this knowledge into man. Therefore, if he didn't want it done, it wouldn't have happened, to get to the other side of it. It's like a bottomless pit here. I've had discussions of this with people, and you can't argue with them.

\section{Specific comments to express reactions to synthetic biology readings ${ }^{8}$}

In reaction to the reading materials on synthetic biology, participants expressed relative ambivalence about the "engineering" nature of synthetic biology and the goal of re-designing life forms. One of the male participants expressed this ambivalence in the following terms: "The prospect excites me; I think it has to do with attempting to create something from nothing, or from very little. I feel it could be beneficial to us. It could also be dangerous if we do not research it enough to find out any long-term effects."

\footnotetext{
${ }^{8}$ American press analysis identified a heavy focus on engineering metaphors and inter alia the term "designer organisms" to describe synthetic biology. American press analysis show that metaphors illustrating the "playing God" or "creation of life" aspects of the technology were employed, as well, but usually in reports emphasizing its potential risks (Pauwels and Ifrim 2008, p. 12). Some of the headlines of the American newspapers speak for themselves: "As DNA research advances, science plays God ever more; New life forms-The line between biological and artificial is about to blur as life is synthesized in labs with man-made genetic material" (The Seattle Times, December 24, 2007); "Scientists enter brave new world of synthetic life" (The Houston Chronicle, December 17, 2007); "Synthetic DNA on the brink of yielding new life forms" (The Washington Post, December 17, 2007).
}

Other comments revealed discomfort with the term "synthetic biology" and fears about the technology being used in a negative way: "This term [synthetic biology] makes me feel scared. This could lead to huge scientific advances, but it can also lead to countries or people using it for their own 'evil agendas.' It reminds me of Jurassic Park."

Another area of uneasiness for the participants was the idea of synthetic biology being used in "creating life." One of the female participants expressed her apprehension by highlighting her uncertainties about researchers being able to control or manage such experiments: "I feel concerned because, not being perfect, we believe we know what is best in creating life. As in science-fiction movies, when we doin time-it goes in a direction we didn't think about...I believe when life is created it is meant to be created that way for a purpose we may not even know right now."

The discussion about the possibility of creating new genetic code and its subsequent instrumental use seemed to provoke a general feeling of discomfort among the participants: "This 'synthetic biology' involves engineering of genetic codes, requisites to genetic engineering. I mean, it seems like, to me, that with this, you don't even need a base DNA. You just create it. [...] I don't like it"; "Making a brand new code, I think it is dangerous."

Although feeling positive about the field's possible applications, one of the male participants expressed his moderate concern about the limits of synthetic biology: "It may be highly profitable. Maybe it could be used to extend life. It seems exciting, but makes me somewhat uncomfortable. Where are the limits?" This intuitive feeling of discomfort led one of the male participants to question the limits of human agency with the well-known "playing God" argument: "It sounds like we are playing God. Who are we as humans to think we can design or redesign life? It might be nice to be able to do so, but is it right? It seems there are many ethical and moral issues. Perhaps we are getting too arrogant." The expression "playing God" was used by three different participants in focus Group 2 .

\section{Potential applications matter}

Another relevant element in the framing process of emerging technologies-and this appears to be the case in the focus groups on synthetic biology - is that applications matter. Potential applications of the technology in question continue to frame public perception.

In the third phase of the focus groups, participants were provided with several specific examples of how synthetic biology is either currently being used or is being developed. Among these specific examples, participants were invited to circle what application they considered most promising. Synthetic biology, of course, spans a very wide range of potential applications from health to energy and 
Table 2 Overall rankings of potential applications of synthetic biology ${ }^{\mathrm{a}}$

${ }^{\text {a }}$ Percentages reflect the number of participants in each group who valued the given application the most

\begin{tabular}{lll}
\hline $\begin{array}{l}\text { Potential applications } \\
\text { of synthetic biology }\end{array}$ & $\begin{array}{l}\text { Focus Group 1 (female } \\
\text { participants, } n \text { female }=11)(\%)\end{array}$ & $\begin{array}{l}\text { Focus Group 2 (male } \\
\text { participants, } n \text { male }=9)(\%)\end{array}$ \\
\hline Biofuels & 36 & 44 \\
Drugs for treating diseases & 9 & 33 \\
New ways to treat cancer & 27 & 11 \\
Sensing harmful contaminants & 0 & 0 \\
Cleaning up the environment & 27 & 11 \\
\hline
\end{tabular}

environment, and the examples we provided to the participants reflected this diversity. As might be expected, the type of synthetic biology application influences the form of the discussion, anticipated reservations, and conclusions. Table 2 presents the rankings of potential applications of synthetic biology according to participants' priorities. As shown by this ranking, both medical and energy prospects were equally promising to the focus groups' participants when invited to select applications. ${ }^{9}$ However, interestingly, when it came to more in-depth discussions of the technology's prospects, participants in both focus groups were far more easily engaged in positive debates about energy than health applications.

In both focus groups, the top-ranked application of synthetic biology was creating new, cheaper, and cleaner sources of energy. Four participants in each focus group chose "biofuels" as the most promising application. In Focus Group 1, one female participant expressed her enthusiasm by saying: "Sounds great, good deal, biofuels, I love that." Comments from male participants echoed this enthusiasm: "I really like the idea of generating, constructing a bacteria to generate hydrogen." Within the energy issue, participants also expressed their concerns about protecting the environment. One of the female participants said: "I like, about the biofuels, how they said it produces cleaner fuels... That could be good as far as going greener for the environment." There was similar concern among male participants: "That [bacteria generating biofuels] would be fantastic, between that and, you know, I believe we have already come up with some bacteria that will eat away stuff in landfills and pollutants and so forth for environmental cleanup. Between those two, I think it would be really helpful to the world."

Participants were more ambivalent about the benefits of medical applications being developed using synthetic biology in the sense that their expectations (e.g. eradicate genetic diseases or cure cancer) were as high as their reluctance to use "engineered" or "re-designed" organisms in their body. The predominant fear for several participants

\footnotetext{
9 As indicated by the American press analysis (Pauwels and Ifrim 2008 , p. 18), potential energy benefits draw almost as much attention as health benefits in news stories about synthetic biology.
}

dealt with possible negative health effects of synthetic biology products used inside the body. One of the female participants stated: "My concern, again, would be injecting anything synthetic inside of my body. That's just where it causes concern for me because I understand they want to do the research for it, but, I mean, I wouldn't want to volunteer, do it on me or my family, so that's what concerns me." Discomfort with the use of synthetic biology products in the human body was also expressed by male participants, among them: "Biofuels sound promising, but, you know, some of the other stuff, about injecting into the body, in the site of a cancer to attack the tumor. Anybody see...I don't know... what could happen with something like that?"

Discussing synthetic biology medical and environmental applications more in-depth, participants expressed distinctly negative reactions to the terms "synthetic" and "construct." As explained by one of the female participants: "I crossed out the word 'construct.' It just kind of bothers me when you're thinking about, you know, especially things that you're putting into your body. The word 'construct' just doesn't sound natural, and it doesn't sound like what's supposed to be going on." The following quote of a male participant gives better insight into why the word "construct" epitomizes some of his concerns related to biosafety: "So, you know, if you modify a bacteria, I'm not a scientist, so if you modify something, at least it's already been here, so it still hopefully maintains some of its original properties. But talking about constructing something that has never existed in environment before and then releasing it into the environment, to me, that's dangerous because in all reality, you really have no idea what's going to happen once it gets into the environment."

As the discussion about the potential applications of synthetic biology included, in both focus groups, some of the participants' concerns, the next section analyzes more in-depth the perceived risks of synthetic biology.

Perceived risks of synthetic biology

This section deals with the question of how the focus group participants framed perceived risks of synthetic biology. In general, these perceived risks were linked to 
the difficulty of managing unknowns, human and environmental concerns, and long-term effects. "Unknowns" and "long-term effects" apply to concerns for which outcomes and effects cannot be predicted by anyone, including experts in synthetic biology. This category includes concerns such as "unknown risks and consequences," "unintended uses," "how our manipulation will effect natural laws," and "unpredictability if synthetic biology follows its own natural laws." Only a few participants' comments were illustrating what experts call biosecurity concerns. ${ }^{10}$

The main concern raised by the participants and discussed at length regarded possible effects of synthetic biology on the environment. In most cases these concerns took the form of questions like: "What happens to synthetic microbes after their useful life is over?" and "What effect would they have in the environment?" One male participant, for example, vocalized concerns with the development of biological systems to target environmental pollution: "Well, for instance, the example of that if they create a bacteria that's going to eat the oil slick, and we know after throwing the bacteria on the water, it's going to die after so many hours in the temperature of the water that's there, if we know that's going to happen without a doubt, then I would be okay with it. But if we don't know..." This biosafety concern was echoed by several female participants. One of them said: "My concerns were the harming of the environment and the unexpected results and side effects. This is kind of scary."

The discussion rapidly led to a related issue-the longterm effects of synthetic biology research and unknowns. After learning what experts in the field of synthetic biology have identified as potential risks associated with development of the technology, one of the female participants expressed her reluctance: "They identify a lot of risks, but then they also use words that, things like might, potentially...there are questions. So there's all the advancement. They don't know what the side effects are going to be, and they may not be able to research it until these things have been around for 20-30 years. And at that point, it may be too late. So I think there's too many might's and too many possibly's for me to feel totally comfortable." A similar concern was expressed by a male participant: "You can put something out, and it looks great, and then you find 2 years down the road that, it's an organism, and it starts to mutate, and now they can't control it, and now you run into this

\footnotetext{
${ }_{10}$ At this stage, it may interesting to notice that, when it comes to potential risks associated with synthetic biology, the American press was primarily focused on biosecurity risks, with ethical concerns coming in second and receiving approximately half as many mentions as biosecurity (Pauwels and Ifrim 2008, p. 19).
}

other problem. It's almost ... because if it gets totally out of hand like nuclear proliferation..." Some participants were more assertive, like this man who exclaimed: "They're dealing with chaos. They're dealing with the unknown."

Linked to the issue of the unknown impact on health and the environment was the issue of "who is in charge?"- the idea that the level of security of technological development intrinsically depends on "whose hands it is in and what they intend to do with it, the potential being limitless, depending on intentions." Usually this concern takes the form of questions like: "And I think the biggest concern would be who would be controlling the people that are doing this?" and "Who or what factor should be the motor and implementer of these inventions?" One of the male participants was particularly afraid of the technology being used for evil purposes-what can be associated with biosecurity concerns. His argument was very simple-other countries are probably working on synthetic biology, and those whose purposes are less than pure, whether foreign or domestic, could easily obtain the technology. Here is his comment: "Who has the knowledge and information? How far would they go with it? I mean, even though we have, in this country, we have laws about scientists efforts, but, I mean, what's to stop a scientist who says, well, I'll make this bacteria and this organism and, well, I can't do it in the United-States, so let me go over to some Third World country where they don't give damn."

Finally, both groups expressed a concern that we should not be "messing with" God's creation, natural selection, or what is human. The argument was often expressed in simple terms: "I mean, you know, again, when man has tried to play God, it's always been disaster, you know, because this is, we don't foresee that take place in nature." One of the female participants was able to elaborate, raising questions about the ethics of creating life: "I just want to say that I think the overall goal is good, the quality of life and making things cheaper and easier, and I guess, for me, the biggest concern is the ethics. You know, who would determine, the last bullet here was talking about life, and it makes me think who determines if this is life or... if we move forward with this, then who sets the boundaries within whatever it is that they are doing? And then who would protect whatever a project would be?" This is echoed by another female participant: "I was going to add the exact same thing, the moral and ethical boundaries are just-who is going to set them?"

Recurring concerns with letting synthetic biology research develop solely within the context of self-regulation by the scientific community led to the examination of what participants' attitudes were regarding the best approach to managing the risks associated with synthetic biology. 
Trust in stakeholders and government actors to regulate synthetic biology

In the final phase of the focus groups, participants' attitudes towards federal regulatory agencies and other potential actors in the regulation of synthetic biology were explored.

\section{Best approach to managing the risks associated with synthetic biology}

Participants were invited to discuss some different potential approaches to how society might try to manage the risks associated with synthetic biology. The results are reflected in Table 3.

Although both groups were skeptical of the ability of the federal agencies to regulate the field, oversight by the government was most often chosen as the best way of regulating synthetic biology. Here is a comment from a male participant: "I feel [federal government] it's the best approach because I don't agree with banning it [the technology]. Technology should advance, and in order to advance, you have, there's risks with it. Just anything that we have today comes at a risk. But I don't trust, you know, I think of the four, that the federal government would be the best. And I guess it would be more in the spotlight than just some private company and its investors." He continued his explanation by referring to the broad principle of political accountability: "At least the government, technically, we choose the government, so if they screw up, we can vote them out of office. And with all of the people on television discussing everything, it's probably harder for the government to white wash an issue as opposed to a private company."

\section{Propositions for increasing public trust}

After having discussed with the participants the best approach to managing the risks associated with synthetic biology, the focus groups' moderator asked questions concerning ways the federal government could work to increase public trust. The concern over the competence of regulatory agencies to handle synthetic biology brought out many suggestions that scientists and/or research institutions needed to participate in oversight along with the regulatory agencies. One of the female participants expressed her reason for involving scientists in the regulatory process: "I think they should be part of the team because they bring so much knowledge and understanding." The reasons for this suggestion were as much about keeping the regulation of synthetic biology above the political fray as it was about involving experts in the regulatory process.

Participants also spoke about enacting a "hybrid" approach, a kind of private-public partnership that would lead to a better system of "checks and balances." As mentioned by one of the female participants: "I guess I would feel more comfortable if there was a system of checks and balances ... like the government, not that that's my first choice, but it seems like it's the only independent option for checking, a system of checks and balances." One of the male participants went even further: "So, we're going to have to set up, I believe, a total new framework of so-called commissions and oversights." Another male participant mentioned the idea of having a third-party overseeing the industry activity: “... regulation by having a third party, an unrelated organization, watch over the industry. And that's why we have them, because they have no interest. They are not connected. They are not getting any profit. They are there to certify or check, independent of those who are making the money." This idea of a system of checks and balances seemed to be, for one of the male participants, the best way of securing accountability and providing the public with information about the research applications: "The knowledge that should something go wrong, there will be repercussions, the checks and balances thing, just so long as if you know anything goes wrong, someone will be held accountable. They won't be just buying their way out of it. There will be a nice little way to know."

\section{Discussion}

The present article is only the starting point in the critical task of understanding how public attitudes toward synthetic

Table 3 Best approach to managing the risks associated with synthetic biology ${ }^{\mathrm{a}}$

\begin{tabular}{lll}
\hline $\begin{array}{l}\text { Best approach to manage the risks associated } \\
\text { with synthetic biology }\end{array}$ & $\begin{array}{l}\text { Focus Group 1 (female } \\
\text { participants, } n \text { female }=11)(\%)\end{array}$ & $\begin{array}{l}\text { Focus Group } 2 \text { (male } \\
\text { participants, } n \text { male }=9)(\%)\end{array}$ \\
\hline $\begin{array}{l}\text { Require the federal government to regulate synthetic biology } \\
\text { Allow the scientific community and others involved }\end{array}$ & 36 & 44 \\
$\quad$ in advancements to regulate synthetic biology & 55 & 0 \\
Ban the further development and use of synthetic biology & 9 & 44 \\
$\begin{array}{l}\text { Allow companies and private funders investing in R\&D } \\
\quad \text { to regulate synthetic biology }\end{array}$ & 0 & 11
\end{tabular}

${ }^{a}$ Percentages reflect the number of participants in each group in favor of described approach 
biology are emerging and how they will further evolve in the coming decades. A number of issues remaining to be investigated follow for those interested in analyzing public perceptions of cutting-edge biotechnologies:

- Finding only some support for the "familiarity argument"-according to which support for emerging technologies will likely increase as awareness of them develops - this article suggests that analogs to cloning, genetic engineering and stem cell research appear to be recurrent in the framing process of synthetic biology. The domain of application seems to be another decisive factor in the framing of synthetic biology.

- Within both focus groups' discussions, a majority of participants expressed reluctance regarding the "playing God" or "creation of life" aspect of synthetic biology. Unanswered by this analysis is the question of the nature of the claims raised by this argument: does it refer to polarization involving broad cultural/philosophical dimensions or to polarization strictly linked to religious values? The unease expressed during the discussions by the focus groups' participants about the "creation of life" aspect of synthetic biology do not allow us to determine if this uneasiness is strictly linked to religious concerns or embodies an array of philosophical, religious, and cultural arguments. Indeed, the "creation of life" aspect was used in the focus groups' discussions by both non-believers and participants defining themselves as coming from a religious background. The question of the influence of belonging to a specific religion on the framing process of synthetic biology and its implications should be tested further in appropriate experimental studies across groups from different geographic locations in the United States and from different religious backgrounds.

- The acceptance of the risk-benefit tradeoff of synthetic biology seems to depend on having an oversight structure that would prove able to manage unknowns, human and environmental concerns, and long-term effects.

The most important conclusion of this article is the need for additional investigation of different factors that will shape public perceptions about synthetic biology, its potential benefits, and its potential risks. Future analysis of the framing process of emerging technologies will require a range of interdisciplinary methods that are perceptive of cultural values and the context of applications. This would help scientists continue a winning strategy of listening to public concerns on research-and responding appropriately-so they can maintain the public trust, leading to better co-evolution of science and society.

Acknowledgments Research for this paper was also supported by the Fonds National de la Recherche Scientifique (FNRS) in Belgium. The author has no commercial relationships or conflicts of interest related to this research. No corporation influenced the design of this study. Correspondence and requests for materials should be addressed to Eleonore Pauwels (eleonore.pauwels@wilsoncenter.org).

Open Access This article is distributed under the terms of the Creative Commons Attribution Noncommercial License which permits any noncommercial use, distribution, and reproduction in any medium, provided the original author(s) and source are credited.

\section{References}

Bauer MW, Allum NC, Miller S (2007) What can we learn from 25 years of PUS survey research? Liberating and expanding the agenda. Public Underst Sci 16: 79-95. http://pus.sagepub.com/ cgi/content/abstract/16/1/79

Douglas M, Wildavsky A (1982) Risk and culture. University of California Press, Berkeley

Gaskell G et al (2004) GM foods and the misperception of risk perception. Risk anal 24: 185-194. http://www.oeaw.ac.at/ita/ ebene5/HT_1242.pdf

Hart Research Associates (2008) Awareness of and attitudes toward nanotechnology and synthetic biology. http://www.synbioproject. org/process/assets/files/6019/hart_final_re8706b.pdf

Kahan DM et al (2008a) Biased assimilation, polarization and cultural credibility: an experimental study of nanotechnology risk perceptions. PEN Brief N. 3 (Project on Emerging Nanotechnologies, 2008). http://www.nanotechproject.org/process/assets/ files/5960/brief2kahan_final.pdf

Kahan DM et al (2008b) The cultural cognition of synthetic biology risk perceptions: a preliminary analysis. GWU Legal Studies Research Paper N. 446. Available at SSRN: http://papers.ssrn. com/sol3/papers.cfm?abstract_id=1264804

Kahan DM et al (2009) Risk and culture: is synthetic biology different? Harvard Law School Program on Risk Regulation Research Paper No. 09-2. Available at SSRN: http://ssrn.com/ abstract $=1347165$

Macoubrie J (2006) Nanotechnology: public concerns, reasoning and trust in government. Public Underst Sci 15:221-241

Pauwels E, Ifrim I (2008) Trends in American and European press coverage of synthetic biology: tracking the last five years of coverage. Synbio 1 (Synthetic Biology Project, 2008). http://www. synbioproject.org/process/assets/files/5999/synbio1final.pdf

Scheufele DA et al (2008) Religious beliefs and public attitudes towards nanotechnology in Europe and the United States. Nat Nanotechnol 361:1-4 